\title{
ICT-Enabled Sharing Economy and Environmental Sustainability-A Resource-Oriented Approach
}

\author{
Pouri, Maria ; Hilty, Lorenz
}

\begin{abstract}
Information and communication technology (ICT) has transformed our consumption patterns. The widespread use of smart devices has enabled practicing a wide variety of "sharing economy" activities, a development that brings new ways of resource consumption to our everyday life. The increasing participation in sharing economy activities calls for studies that research the sustainability of this new consumption trend. Although the concept is associated with a more collaborative resource consumption, this may in practice be limited to some resources being shared. The present paper sets the stage for better understanding of the ICT-enabled sharing economy in the context of environmental sustainability. In this work, we present a line of thought that starts with perceiving resource sharing as the core of the sharing economy and continue with a sustainability analysis using a conceptual framework of ICT impacts on sustainability. This study provides a first step towards conceptualizing the sharing economy in a sustainability context and delineates further analysis of the sustainability of digital sharing.
\end{abstract}

DOI: https://doi.org/10.1007/978-3-319-99654-7_4

Posted at the Zurich Open Repository and Archive, University of Zurich

ZORA URL: https://doi.org/10.5167/uzh-158680

Book Section

Accepted Version

Originally published at:

Pouri, Maria; Hilty, Lorenz (2018). ICT-Enabled Sharing Economy and Environmental Sustainability-A ResourceOriented Approach. In: Bungartz, Hans-Joachim; Kranzlmüller, Dieter; Weinberg, Volker; Weismüller, Jens; Wohlgemuth, Volker. Advances and New Trends in Environmental Informatics. Cham: Springer (Bücher), 5365.

DOI: https://doi.org/10.1007/978-3-319-99654-7_4 


\title{
ICT-Enabled Sharing Economy and Environmental Sustainability - a Resource-oriented Approach
}

\author{
Maria J. Pouri ${ }^{1}$ and Lorenz M. Hilty ${ }^{1,2}$ \\ ${ }^{1}$ Department of Informatics, University of Zurich, Switzerland \\ ${ }^{2}$ Technology and Society Lab, Empa Materials Science and Technology, Switzerland \\ pouri@ifi.uzh.ch, hilty@ifi.uzh.ch
}

\begin{abstract}
Information and communication technology (ICT) has transformed our consumption patterns. The widespread use of smart devices has enabled practicing a wide variety of "sharing economy" activities, a development that brings new ways of resource consumption to our everyday life. The increasing participation in sharing economy activities calls for studies that research the sustainability of this new consumption trend. Although the concept is associated with a more collaborative resource consumption, this may in practice be limited to some resources being shared. The present paper sets the stage for better understanding of the ICT-enabled sharing economy in the context of environmental sustainability. In this work, we present a line of thought that starts with perceiving resource sharing as the core of the sharing economy and continue with a sustainability analysis using a conceptual framework of ICT impacts on sustainability. This study provides a first step towards conceptualizing the sharing economy in a sustainability context and delineates further analysis of the sustainability of digital sharing.
\end{abstract}

Keywords: Information and Communication Technology, Sharing Economy, Digital Platforms, Consumption, Sustainability.

\section{Introduction}

Information and communication technology (ICT) has transformed the ways we produce and consume. In particular, the widespread use of smart devices has enabled practicing a wide variety of "sharing economy" activities among people, both locally and globally. Digital platforms provide a more rapid (accessed through digital devices), low cost (no/low intermediary costs), and creative (innovative forms of offering services) way for practicing the sharing economy and sharing resources.

The basic idea behind the sharing economy is to promote the utilization of available and underused resources, such as transportation means, accommodation, or consumables. The economic activities necessary for providing these goods have - over their whole life cycle, from "cradle to grave" - an impact on the use of natural resources, since economic systems and the environment are closely interrelated [e.g. in 1-3]. The increasing trend in using natural resources already surpassed sustainable levels and the disruption of environmental systems is stated to be one of the crucial

\section{This Accepted Author Manuscript is copyrighted by Springer.}

Citation: Pouri, M.J., Hilty, L.M.: ICT-Enabled Sharing Economy and Environmental Sustainability - a Resource-oriented Approach. In: Bungartz, H.J, Kranzlmüller, D., Weinberg, V., Weismüller, J., Wohlgemuth, V. (eds.) EnviroInfo 2018. Progress in IS. Springer International Publishing (2018). 
consequences of increasing resource use [4]. As a subsequent effect, environmental deterioration affects economies and economic growth as increasing use of natural resources may end up with higher resource prices and damaged environmental systems [4].

According to the original definition, also known as Brundtland definition, sustainable development is a type of development that "meets the needs of the present without compromising the ability of future generations to meet their own needs" [5]. Given the fact that mankind is using some non-renewable resources (e.g. fossil fuels and many metals) in an irreversible way, as well as some renewable resources (e.g. water and soil) at a rate that is higher than their regeneration rate, the currently prevailing patterns of production and consumption are not sustainable. By continuing them, we are putting a high burden on future generations. All artefacts we are directly using as resources are produced by production systems that exchange material and energy with the environment and are therefore based on the use of natural resources, even if the natural "resource" consists in the ability to absorb some residuals, such as solid waste or emissions into water and air. Even today, the consumption patterns of the richest 20 percent of human society do not scale to the world population, a fact which creates an ethical dilemma between inter- and intragenerational justice [6].

The increasing trend in resource consumption calls for new ways that could significantly change the prevailing unsustainable resource consumption practices. One way to achieve or maintain economic prosperity without increasing environmental damage is "decoupling" [4,7]. Decoupling dissociates economic growth from use of natural resources, i.e. greater economic value is gained from fewer material and energy resource inputs [4]. Technological innovation creates potentials for the substitution or more efficient use of resources, which is a necessary (however not sufficient) condition for decoupling [8]. The sharing economy is an example of a phenomenon driven by technological change and innovation that allows to optimize the use of existing resources. It is enabled by ICT-based platforms (technology) that provide new ways of access to and use of resources through new business models and services (innovation).

Although the environmental benefits of the sharing economy appear to be obvious - because it increases the utilization of existing resources and therefore moderates the need for new resources and products - there is not much clear and explicit evidence that could bolster this assumption. Theoretical arguments exist that challenge the assumption, in particular relating to rebound effects [9]. To date, in the sustainability and economy literatures, empirical evidence for sustainability effect of the sharing has remained scarce and a research gap in investigating those implications is still considerable [10]. Throughout the present study, by sustainability, we mean sustainable use of resources. Studying new patterns of providing and consuming goods and services from a sustainability perspective is important, and the digital sharing economy is not excluded from this requisite. It should be sufficiently addressed under which conditions and to what extent the sharing consumption mode in the digital economy can contribute to sustainability.

The environmental and sustainability contributions of the sharing economy appear to be anecdotal; there are not enough dependable empirical studies on such contribu- 
tions. In addition, a lack of adequate conceptualizations of the sharing economy phenomenon within the sustainability context may lead to imperfect studies and results. The present work aims to set the stage for better understanding of the digitally enabled sharing economy in the context of environmental sustainability. To achieve this, we introduce a line of thought that starts with perceiving resource sharing as the core of the sharing economy which is then extended further to a systematic sustainability analysis using a conceptual framework obtained from the literature. The preliminary results of this study reveal the demand for deeper analysis of the sustainability contribution of sharing.

\section{Conceptualizing the Sharing Economy}

Various definitions for the sharing economy have been presented in the studies of scholars in this area as well as areas pertaining to it. There have been levels of ambiguity and even confusion to define the sharing economy [11] owing to the relative novelty of the concept of sharing in its digital form. Some authors have already critically reviewed the presented definitions for the sharing economy (see e.g. [12]). Therefore, it is hard to find a widely accepted definition for the sharing economy to refer to [13,14].

While some scholars distinguish between the business-to-consumer and customerto-customer activities (e.g. [15,16,17 cited in 18]), most of the definitions for the sharing economy are compatible in acknowledging the peer-to-peer or actor-to-actor nature of sharing activities. In addition, all types of the contemporary sharing economy share a common aspect; they all run on ICT-based platforms. In practice, digital sharing economy activities are conveyed via information systems and facilitated by technology-driven platforms, making the sharing economy suitable to be mainly studied as a technological phenomenon [19]. The digital sharing economy is rich in incorporating manifold market-based and service innovations, such as platforms for providing temporary access to accommodation, car/ride renting and sharing services, and platforms for sharing resources in local communities [20]. Digital platforms of the sharing economy are of socio-economic significance because they 1) "connect people that would not otherwise do business together, 2) create economies of scale to bring together supply and demand, and 3) mediate in the relationship between supply and demand..." [21, p. 3438]. Although the sharing economy is in fact an application of ICT, it is also a business/commerce concept that has been enabled in its current form by ICT. Therefore, in order to define it more precisely, we should consider both aspects of the contemporary sharing economy at a time. As a result of the combination of economic and technological aspects, the actions of sharing become interesting to investigate. A comprehensive perspective to define the digital sharing economy could be then to recognize it as a techno-socio-economic phenomenon.

Some studies (e.g. $[13,14]$ ) have provided an overview of the existing definitions of the sharing economy concept already presented in the literature. Pouri and Hilty [22] propose a unified definition for the ICT-enabled sharing economy: "A digital sharing economy is a resource allocation system, based on sharing practices, that is 
enabled by information and communication technology (ICT) and coordinated through participation of individuals and possibly commercial organizations (businesses) with the aim to provide temporary access to resources that may involve either direct or indirect monetary value". This definition describes the sharing economy as a "techno-socio-economic" concept.

The relationship between the sharing economy and sustainability has captured attention and triggered some academic debate (e.g. [19,20,23-25]) in recent years. Since demographic growth and increasing global resource scarcity have been raising sustainability concerns - in particular environmental concerns - for decades, the digital sharing economy seems to provide new alternative ways for the existing consumption patterns [26], and thus for the goal of decoupling. Potential sustainability benefits for the environment associated with the sharing economy have been pointed out [e.g. 27] with the shared or collaborative consumption being the key part of it. Generally, the sharing business models are seen as promisingly sustainable [28] and having the potentiality to shift local and global economies towards sustainability [27]. A closer look, however, indicates that the sustainability prospects of sharing may not be simply generalizable to the whole economy.

\section{Sustainability of Shared Resources}

The concept and practice of the sharing economy has the potential for promoting sustainability in a society [23]. However, although the concept is associated with a more collaborative resource consumption, it may in practice be limited to some resources being shared. The sharing economy has been innovative in utilizing underused assets, and environmentally useful through intensifying the capacity utilization of existing assets. It can foster sustainability through encouraging efficient use of resources while creating economic value for people [18]. Although it is claimed that social interaction, social cohesion and extraction of values from underutilized assets in the sharing economy would promote environmental sustainability and sustainable development per se [18], this is only one side of the scenario. Identifying and quantifying how environmentally relieving the digital sharing economy is still remains challenging and not straightforward to study [29], especially that evidence to sustainability contribution of it has remained scarce.

There is not much data to judge upon whether sharing platforms actually lower the environmental impacts and footprints in long spans. For example, Airbnb claims considerable decrease in energy and water consumption as well as decrease in greenhouse gas emissions by people choosing to stay in its properties [30]. However, the company does not present its claim with enough evidence and avoids revealing the details on how and based on what study it has reached to such results, rendering the validity of such claims questionable. In a long-term perspective, even if Airbnb or other similar platforms will already have decreased energy consumption through their accommodations, it will remain unclear if such a trend would last with an increasing use of its 
housings ${ }^{1}$. In addition, a broader point of view would be to study, e.g., how low-cost and affordable housing prices would affect travel and flight rates. In other words, affordable accommodation may enable people to use more of air travel - which would be a classical rebound effect -, raising concerns about the energy consumption and carbon footprint of air travel. Therefore, the long-term effects of such instances of the sharing economy to sustainability are difficult to anticipate [32].

A problem with simple assumptions and early conclusions about the sharing economy bringing sustainability is that such statements are too general to be applied to every specific type of the sharing economy. Certainly, sharing resources can create a significant value by increasing capacity utilization of existing resources, but not all the resources are simple enough to be assessed in the same way. Considering the fact that the sharing economy embraces a vast variety of resources, from goods to services, an approach to research whether shared consumption practices are, or could be, sustainable is to study how sharing a particular resource may affect the sustainability of its consumption. By classifying the resource types of the sharing economy and then channeling them into a sustainability analysis, we intend to reach a more dependable analysis and realistic conclusions about the sustainability impact of the digital sharing economy. The first step in studying the nexus between the sharing economy and sustainability is specifying and categorizing the sharing economy by the type of resources being shared (Table 1).

\footnotetext{
${ }^{1}$ Studies can be found (e.g. [31]) that suggest Airbnb is more sustainable than traditional travel lodging as it consumes less resources and produces less waste.
} 
Table 1. Different types of resources being shared in sharing economy systems

\begin{tabular}{|c|c|c|c|}
\hline $\begin{array}{l}\text { Type of } \\
\text { resource for } \\
\text { connected } \\
\text { consumption }\end{array}$ & Explanation & Example of resources & Example of platform \\
\hline \multirow[t]{6}{*}{ Tangible assets } & \multirow[t]{5}{*}{$\begin{array}{l}\text { Provides access to } \\
\text { physical, durable } \\
\text { goods and } \\
\text { intensifies the } \\
\text { utilization of them }\end{array}$} & $\begin{array}{l}\text { Transportation means } \\
\text { Car sharing } \\
\text { Ride sharing } \\
\text { Ride services } \\
\text { Bicycle sharing }\end{array}$ & $\begin{array}{l}\text { Turo, Getaround, Zipcar } \\
\text { Zimride [17, 33] } \\
\text { Uber [17, 34], Lyft [17] } \\
\text { Liquid }\end{array}$ \\
\hline & & $\begin{array}{l}\text { Logistics [32] } \\
\text { Local delivery } \\
\text { Shipping }\end{array}$ & $\begin{array}{l}\text { UberRUSH } \\
\text { Shipster }\end{array}$ \\
\hline & & $\begin{array}{l}\text { Accommodation } \\
\text { Room/house }\end{array}$ & Airbnb, Couchsurfing $[19,34]$ \\
\hline & & $\begin{array}{l}\text { Tools [35] } \\
\text { Household goods }\end{array}$ & Peerby \\
\hline & & $\begin{array}{l}\text { Space }^{2} \\
\text { Land } \\
\text { Office space } \\
\text { Parking, storage }\end{array}$ & $\begin{array}{l}\text { LandShare } \\
\text { WeWork [34] } \\
\text { ParqEX }\end{array}$ \\
\hline & $\begin{array}{l}\text { Provides } \\
\text { affordable access } \\
\text { to consumables } \\
\text { and non-durable } \\
\text { goods and products }\end{array}$ & $\begin{array}{l}\text { Consumables } \\
\text { Food [34] } \\
\text { Clothes }\end{array}$ & $\begin{array}{l}\text { OLIO } \\
\text { YCloset }\end{array}$ \\
\hline \multirow[t]{5}{*}{$\begin{array}{l}\text { Intangible } \\
\text { assets }\end{array}$} & \multirow{5}{*}{$\begin{array}{l}\text { Provides services } \\
\text { to access to } \\
\text { expertise, skill and } \\
\text { time as shareable } \\
\text { resources }\end{array}$} & $\begin{array}{l}\text { Expertise/education/language } \\
\text { providing access to knowledge, } \\
\text { personalised learning, etc. }\end{array}$ & $\begin{array}{l}\text { SkillShare [17], Coursera [34], } \\
\text { italki }\end{array}$ \\
\hline & & $\begin{array}{l}\text { Skill/service } \\
\text { Hiring people to do small tasks or services } \\
\text { (matching "taskers" with demand in a local } \\
\text { community) }\end{array}$ & TaskRabbit \\
\hline & & $\begin{array}{l}\text { Time (time-based currency }{ }^{b} \text { ) } \\
\text { Using units of time as currency, equal for } \\
\text { all users disregarding the type of act, help } \\
\text { or task }\end{array}$ & hOurworld \\
\hline & & $\begin{array}{l}\text { Content/information/impact }{ }^{c} / \text { reputation }^{\mathrm{d}} \\
\text { Peer-to-peer file sharing } \\
\text { Review on service providers } \\
\text { Review on tourism services } \\
\text { Ranking social impact/influence } \\
\text { Providers' rank and reputation [32] }\end{array}$ & $\begin{array}{l}\text { The Pirate Bay [19] } \\
\text { Yelp } \\
\text { Tripadvisor } \\
\text { Klout }\end{array}$ \\
\hline & & $\begin{array}{l}\text { Connection } \\
\text { WiFi }\end{array}$ & Fon \\
\hline Money & $\begin{array}{l}\text { Provides peer-to- } \\
\text { peer financing and } \\
\text { crowdfunding } \\
\text { services }\end{array}$ & $\begin{array}{l}\text { Peer-to-peer lending /micro loans } \\
\text { Crowdfunding }[19,32]\end{array}$ & $\begin{array}{l}\text { Kiva, LendingClub } \\
\text { Kickstarter }\end{array}$ \\
\hline
\end{tabular}

a Definable as a confined entity and an attribute of a physical property, e.g. land, office space, etc.

${ }^{b}$ Although time banking is a component of the sharing economy, it differs from the other examples of 
resource sharing since it basically does not generate income or employment. However, the fact that people participating in time banking are actually saving money by collaboratively helping each other in their social bonds serves as a proof of indirectly added income by not paying for the services they receive.

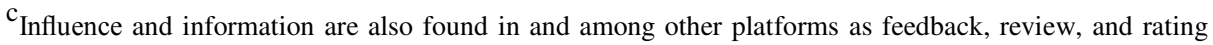
related to a specific shared-resource. ${ }^{d}$ The online platforms aggregate reviews and rank service and goods providers; this could then assist providers in keeping and furthering their economic activity on the platforms. From this viewpoint, the sharing economy can be referred to as a "reputation economy" [36, 37 cited in 32].

The second step is to apply a method for sustainability analysis of the digital sharing economy. We are using the conceptual framework for assessing the environmental impacts of ICT proposed by Hilty and Aebischer [8] (Fig. 1). This typology can be applied to assess the environmental impacts of the digital sharing economy as a lucid example of ICT application in the economy.

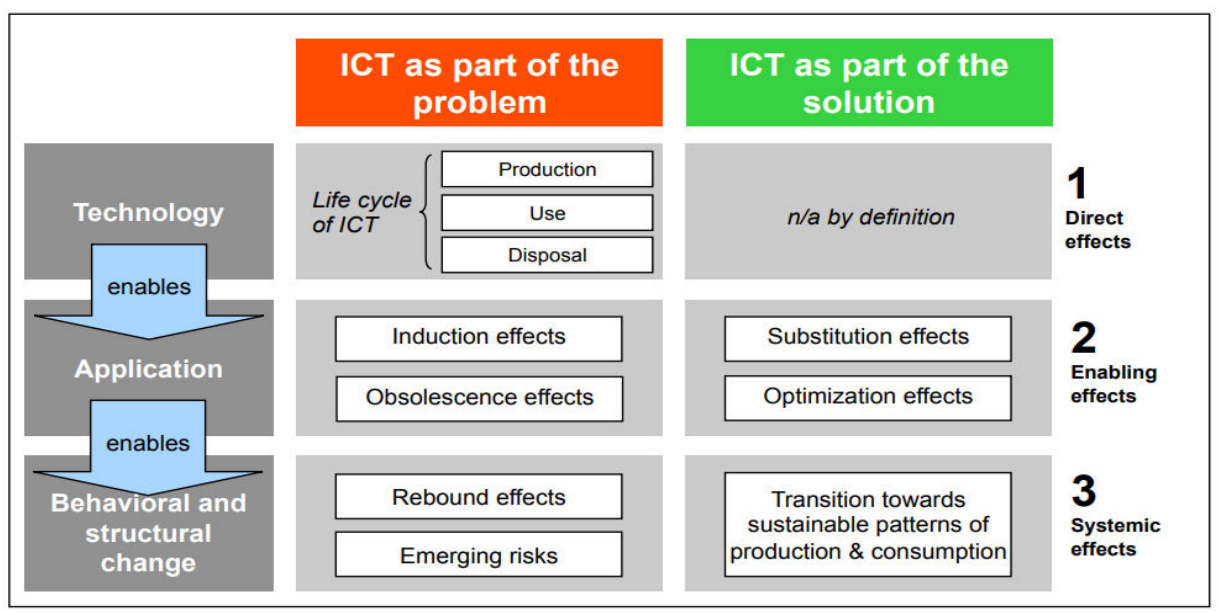

Fig. 1. A conceptual framework for assessing ICT effects (source: [8]).

In this typology, the $1^{\text {st }}$-order or direct effects of ICT refer to the direct environmental impacts of the production, use and disposal of ICTs that also include the demand for material and energy throughout the entire life cycle of ICT hardware and software. Digital sharing platforms use ICT as an enabling technology. They bring digital sharing practices into realization using, e.g., big-data-driven systems to present and trace information on goods, services, consumers etc. In addition, ICT devices, in particular smartphones, have enabled access to peer-to-peer networking and marketplaces for individuals.

ICT itself has been a notable source of environmental impacts, which has to be taken into account also in the digital sharing economy. The lifecycle of ICT equipment consumes energy and materials at different stages, from extracting raw materials, to production phase, to use phase and eventually to the recycling and final dispos- 
al phase. Although the energy efficiency of ICT hardware (also related to software ${ }^{2}$ ) has improved remarkably, the overall energy used for ICT is still increasing, rendering the energy consumption of ICT at issue. This is due to the increasing demand for ICT applications to a degree that has surpassed the improvements in its energy efficiency [40]. To date, there are no specific reports on the energy consumption of the part of data centers that would have to be allocated to digital sharing platforms. As long as no blockchain technology will be used for sharing platforms, we can assume that sharing is one of the ICT use cases which provides a saving potential that clearly overbalances the direct environmental impacts of producing and running the technology, as has been shown for related use cases $[41]^{3}$.

The $2^{\text {nd }}$-order or enabling effects are the indirect environmental impacts of ICT as a result of its application in production processes, consumption services and distribution systems. ICT-based platforms are the enabling technology for the digital sharing economy. Instances of the sharing economy may have favorable or unfavorable impacts from a sustainability perspective. Among the four types of the enabling effects classified by Hilty and Aebischer [8], the induction effects and optimization effects ${ }^{4}$ seem to be most adequate to describe the sustainability impact of the sharing economy in a simplified analysis, or as the first step for a deeper analysis. In an induction effect, ICT stimulates the consumption of resources (even without rebound effects, e.g., just by enabling access or creating complementarity), and in an optimization effect it reduces the use of resources (if this effect is not balanced out by rebound effects).

The digital sharing economy does not introduce new resources; it rather enables an extended mode of consumption of accessible resources. This creates a two-sided environmental effect in the form of both increasing and decreasing the use of particular resources being shared. For instance, compared to hotels, an accommodation sharing platform such as Airbnb may have saved a considerable amount of energy and water use while contributing to substantial waste avoidance, and also to increasing the sustainability awareness of its guest, as reported by Airbnb [30]. In the long run, less buildings will have to be built because the utilization of rooms is higher. Although there are controversies over the validity of such statistics, it is convincing to some degree that sharing would save more energy, material and cost. There is then an induction effect which involves motivating people to use such services because it is so easy to do and these services are complementary to the purely virtual possibilities offered by social networking platforms.

2 The relationship between software characteristics and the demand for natural resources for manufacturing its adequate hardware has received less attention in scientific studies [8]. This is also the case with the sharing economy in which the relationship between its software applications and the required resources for the hardware in the entire system has not been studied to date. First steps into the direction of addressing software sustainability with regard to natural resources have been done by Guldner et al. [38] and Kern [39].

3 For more on the ICT implications for energy consumption see [40, 42-46].

4 In addition to induction effects and optimization effects are obsolescence effects and substitution effects with the former referring to the case where "ICT can shorten the useful life of another resource due to incompatibility", and the latter where "the use of ICT replaces the use of another resource [8, p. 21]. 
The $3^{\text {rd }}$-order effects are defined as systemic effects and are the indirect impacts of ICT on life styles and value systems, which in the long term are crucial for environmental impacts. As explained by Hilty and Aebischer [8], systemic effects are "the long-term reaction of the dynamic socio-economic system to the availability of ICT services, including behavioral change (life styles) and economic structural change [p.22]". This type of effects becomes more prominent in the context of sharing economy in which new patterns for consumption are practiced.

Some advocators of the sharing economy introduce it as a provider of fundamental sustainability visions. They view the sharing economy as a potential pathway to sustainable consumption patterns [20]. This perspective could be interpreted into the $3^{\text {rd }}-$ order effects as potential positive changes in individuals' consumption habits at micro level (lifestyle) and an emerging transformation in socio-economic structures at macro level (structural changes). Some even believe that the sharing economy per se already offers a sustainable, less resource-intensive model of consumption [35] by selling the use rather than selling the product [47].

Here, an issue could be raised with such presumptions. Thinking of the sustainability of the sharing economy is not always about the act of sharing which is naturally associated with less or balanced demand for new things. The resource itself and its quality of being (potentially) sustainable is important too. An intelligible example here could be ride service and car sharing platforms that are expected to reduce the overall demand for cars, their production and energy consumption. However, by cars we do not mean only their physical entity as objects, we mean also their energy consumption and footprint during use, without which any sustainability analysis would turn out to be invalid. What if an increase in car sharing leads to higher levels of road traffic, energy consumption, emissions coming from the cars being shared? Or will car sharing be still environmentally sustainable if it motivates people to opt out of public transportation?

In order to gain a deeper insight into the environmental impacts of the sharing economy and their assessment, one should consider a longer run perspective on the lifecycle of the value obtained through participating in sharing. What would be the broader and long-term scenario for environmental implications of the affordable digital platform economy when people spend the money saved from sharing for highimpact products? This would then possibly create a shift to other unsustainable resources and consumption habits with unknown or new effects on the environment (indirect rebound effect). It is also assumable that when people increase the demand for a product or service because of its lower price, this eventually offsets the beneficial savings created by higher efficiency (direct rebound effect).

From an energy economics perspective, the rebound effect is the result of behavioral and systems' responses to reduced costs in energy efficient measures [48]. In the context of the sharing economy, the energy efficiency of the system is created by sharing what is available, such as cars, and the intensified practice of sharing is the result of the behavioral responses aggregating to the system's reaction. If the rebound effect resulting from such a system is substantial enough, this seriously challenges the plausibility of the hypothesis for sharing economy's contribution to sustainability. 


\section{Discussion and Conclusion}

Like other aspects of the digital economy, the ICT-enabled sharing economy appears to continue imposing its own presence on the existing societal and environmental structures. The digital sharing economy encourages a type of consumption whereby available resources are collaboratively shared and consumed among people via online platforms. This intensified utilization of existing resources brings new patterns of consumption while opening new discussions about the sustainability status of digital sharing. The typical assumptions for the sustainability contribution of the sharing economy, as stated by Demailly and Novel [10], are that 1) shared goods create sustainability because they enable a reduction in the number of goods required to be produced; 2) sharing optimizes transport of goods due to increase in shorter-distance transportation; and that 3) sharing models can direct sustainable patterns of consumption. Although the authors states that the environmental benefits of sharing depend on the conditions for their realization that are highly specific to each sharing model, arguments against the reliability and long-run validity of such general premises can be raised. First, no studies have been spotted yet to declare a decreasing, or decreased, level of production in reality owing to a correspondingly increasing trend in the sharing economy. To be more precise, there are no evidences showing that people's temporary access to goods would eventually lead to their lower demand for or less interest in new products. Second, although sharing can decrease distances in transportation of goods, especially in local sharing systems, this may not be applicable to general. Not all sharing activities run at local level. Recalling the Airbnb case, either at global level or more regional, affordable access to a resource (accommodation) may increase the consumption of other resources (e.g., by travel). Even for the businesses that run at local level, such as car sharing and riding services, increased utilization of a resource (in the case of car sharing, transportation and its fuel consumption) may also encourage an unsustainable consumption trend. Third, the sustainability status of the sharing economy needs a differentiated approach and is not sufficiently studied yet. A hyper-consumption mode created by the sharing economy can be also a scenario [10].

In the present paper, we aimed to initiate a resource-oriented analysis for studying the digital sharing economy in the context of environmental sustainability. We provided examples for tangible resources and attempted to provide an overview for envisioning the sustainability of resource consumption in a sharing system. Nevertheless, tracking a source's trend in (intensified) consumptions is not straightforward, especially for intangible assets. Studying the environmental impacts of sharing intangible resources, namely information, skill, knowledge, workforce etc. has not been widespread in the scientific study and a paucity of scholarly work in this area is observable. Further steps and higher-level analysis for investigating the sustainability of digital sharing, which can include intangible assets, could be viewed through the lens of a more layered model. By using the extended framework for ICT impacts - the model for life-cycle impacts, enabling impacts, structural impacts (LES model), also proposed by Hilty and Aebischer [8] - a deeper analysis of the role of intangible goods such as information might be feasible. This means that the increased level of information generated and distributed over digital platforms may eventually lower the need 
for resources in the whole sharing ecosystem, whereby a substitution effect occurs in replacing tangible assets with increasing level of information.

\section{References}

1. Perrings, C.: Economy and environment: a theoretical essay on the interdependence of economic and environmental systems. Cambridge University Press (2005).

2. Victor, P.A.: Pollution: Economy and environment. Routledge (2017).

3. Stern, N.: The Stern Review. Cambridge: Cambridge University Press (2006).

4. Von Weizsäcker, E.U., de Larderel, J., Hargroves, K., Hudson, C., Smith, M., Rodrigues, M.: Decoupling 2: technologies, opportunities and policy options. A Report of the Working Group on Decoupling to the International Resource Panel. UNEP (2014).

5. WCED, World Commission on Environment and Development: Our common future. Oxford: Oxford Univ. Press. (1987).

6. Hilty, L. M.; Ruddy, T. F.: Sustainable Development and ICT Interpreted in a Natural Science Context: The Resulting Research Questions for the Social Sciences. Information, Communication \& Society 13 (1), 7-22 (2010).

7. Fischer-Kowalski, M., Swilling, M., von Weizsäcker, E.U., Ren, Y., Moriguchi, Y., Crane, W., Krausmann, F., Eisenmenger, N., Giljum, S., Hennicke, P., Romero Lankao, P., Siriban Manalang, A.: Decoupling natural resource use and environmental impacts from economic growth, A Report of the Working Group on Decoupling to the International Resource Panel. UNEP (2011).

8. Hilty, L.M., Aebischer, B.: ICT for Sustainability: An Emerging Research Field. In: Hilty, L.M., Aebischer, B. (eds.) ICT Innovations for Sustainability. Advances in Intelligent Systems and Computing 310, Springer, Cham (2015).

9. Briceno, T., Peters, G., Solli, C., Hertwich, E.: Using life cycle approaches to evaluate sustainable consumption programs: car-sharing. Reports and Working Papers from Norwegian University of Science and Technology (NTNU), Industrial Ecology Programme (IndEcol) (2005).

10. Demailly, D., Novel, A.S.: The sharing economy: make it sustainable. Studies 3 (2014).

11. Frenken, K., Schor, J.: Putting the sharing economy into perspective. Environmental Innovation and Societal Transitions 23, 3-10 (2017).

12. Arnould, E.J., Rose, A.S.: Mutuality: Critique and substitute for Belk's "sharing". Marketing Theory 16(1), 75-99 (2016).

13. Acquier, A., Daudigeos, T., Pinkse, J.: Promises and paradoxes of the sharing economy: An organizing framework. Technological Forecasting and Social Change 125, 1-10 (2017).

14. Breidbach, C.F., Brodie, R.J.: Engagement platforms in the sharing economy: conceptual foundations and research directions. Journal of Service Theory and Practice 27(4), 761777 (2017).

15. Gollnhofer, J.F.: Moral sharing: Teilen zwischen unternehmen und konsumenten, Marketing Review St Gallen 32(4), 40-47 (2015).

16. Möhlmann, M.: Collaborative consumption: determinants of satisfaction and the likelihood of using a sharing economy option again. Journal of Consumer Behaviour 14(3), 193-207 (2015). 
17. Schor, J.: Debating the sharing economy. Journal of Self-Governance \& Management Economics 4(3), (2016).

18. Plewnia, F., Guenther, E.: Mapping the sharing economy for sustainability research. Management Decision 56(3), 570-583 (2018).

19. Hamari, J., Sjöklint, M., Ukkonen, A.: The sharing economy: Why people participate in collaborative consumption. Journal of the Association for Information Science and Technology 67(9), 2047-2059 (2015).

20. Martin, C.J.: Initial steps towards a research agenda for the sharing economy and sociotechnical transitions. Studies 31, 27-41 (2015).

21. Lu, Y., Ou, C., Angelopoulos, S.: Exploring the effect of monetary incentives on user behavior in Online Sharing Platforms. Tilburg University, School of Economics and Management, (2018).

22. Pouri M.J., Hilty, L.M.: Conceptualizing the Digital Sharing Economy in the Context of Environmental Sustainability. Sustainability, Special Issue on Information and Communications Technologies (ICT) for Sustainability (2018), submitted for publication.

23. Heinrichs, H.: Sharing economy: a potential new pathway to sustainability. GAIAEcological Perspectives for Science and Society 22(4), 228-231 (2013).

24. Hasan, R., Birgach, M.: Critical success factors behind the sustainability of the Sharing Economy. In: Software Engineering Research, Management and Applications (SERA), 2016 IEEE 14th International Conference on, pp. 287-293 (2016).

25. Martin, C.J.: The sharing economy: A pathway to sustainability or a nightmarish form of neoliberal capitalism?. Ecological Economics121, 149-159 (2016).

26. Ferrari, M.Z.: Beyond uncertainties in the sharing economy: Opportunities for social capital. European Journal of Risk Regulation 7(4), 664-674 (2016).

27. Cohen, B., Kietzmann, J.: Ride on! Mobility business models for the sharing economy. Organization \& Environment 27(3), 279-296 (2014).

28. Tukker, A.: Eight types of product-service system: eight ways to sustainability? Experiences from SusProNet. Business strategy and the environment 13(4), 246-260 (2004).

29. Rubicon, http://knowledge.wharton.upenn.edu/article/how-green-is-the-sharingeconomy/, last accessed 2018/06/11.

30. Airbnb, https://press.atairbnb.com/app/uploads/2017/03/Airbnbandsustainabletravel2017.pdf, lasr accessed 2018/06/11.

31. Midgett, C., Bendickson, J.S., Muldoon, J., Solomon, S.J.: The sharing economy and sustainability: A case for AirBnB. Small Business Institute ${ }^{\circledR}$ Journal 13(2), 51 - 71 (2016).

32. Ganapati, S., Reddick, C.G.: Prospects and challenges of sharing economy for the public sector. Government Information Quarterly 35(1), 77-87 (2018).

33. Chan, N.D., Shaheen, S.A.: Ridesharing in North America: Past, present, and future. Transport Reviews 32(1), 93-112 (2012).

34. Puschmann, T., Alt, R.: Sharing economy. Business \& Information Systems Engineering 58(1), 93-99 (2016).

35. Belk, R.: You are what you can access: sharing and collaborative consumption online. Journal of Business Research 67(8), 1595-1600 (2014).

36. Fertik, M., Thompson, D.: The reputation economy: How to optimise your digital footprint in a world where your reputation is your most valuable asset. Hachette, UK (2015).

37. Gandini, A.: The reputation economy: Understanding knowledge work in digital society. Palgrave Macmillan, London (2016).

38. Guldner A., Garling M., Morgen M., Naumann S., Kern E., Hilty L.M.: Energy Consumption and Hardware Utilization of Standard Software: Methods and Measurements 
for Software Sustainability. In: Otjacques B., Hitzelberger P., Naumann S., Wohlgemuth V. (eds) From Science to Society. Progress in IS. Springer, Cham (2018).

39. Kern E.: Green Computing, Green Software, and Its Characteristics: Awareness, Rating, Challenges. In: Otjacques B., Hitzelberger P., Naumann S., Wohlgemuth V. (eds) From Science to Society. Progress in IS. Springer, Cham (2018).

40. Aebischer, B., Hilty, L.M.: The Energy Demand of ICT: A Historical Perspective and Current Methodological Challenges. In: Hilty, L.M., Aebischer, B. (eds.) ICT Innovations for Sustainability. Advances in Intelligent Systems and Computing. Springer, Heidelberg (2015).

41. Hilty, L. M.; Bieser, J. T. C.: Opportunities and Risks of Digitalization for Climate Protection in Switzerland. Report, University of Zurich (2017).

42. Fettweis, G., Zimmermann, E.: ICT energy consumption-trends and challenges. In: The 11 th international symposium on wireless personal multimedia communications. Conference Proceedings, Lapland (2008).

43. Mattern, F., Staake, T., Weiss, M.: ICT for green: how computers can help us to conserve energy. In: The 1st international conference on energy-efficient computing and networking. ACM, Passau (2010).

44. Hilty, L., Lohmann, W., Huang, E.: Sustainability and ICT - an overview of the field. Politeia 27(104), 13-28 (2011).

45. Coroama, V.C., Hilty, L.M.: Assessing Internet energy intensity: A review of methods and results. Environmental impact assessment review 45, pp.63-68 (2014).

46. Coroama, V., Hilty, L.M.: Energy consumed vs. energy saved by ICT-A closer look. In Environmental Informatics and Industrial Environmental Protection: Concepts, Methods and Tools, 23rd International Conference on Informatics for Environmental Protection, pp. 353-361, Berlin (2009).

47. Matzler, K., Veider, V., Kathan, W.: Adapting to the sharing economy. MIT Sloan Management Review 56(2), 71-77 (2015).

48. Hertwich, E.G.: Consumption and the rebound effect: An industrial ecology perspective. Journal of industrial ecology 9(1- 2), 85-98 (2005). 